\title{
Microstructure-Property Relationships in Thermomechanically Processed Medium-Mn Steels with High Al Content
}

\author{
Adam Grajcar ${ }^{1, *(\mathbb{D})}$, Andrzej Kilarski ${ }^{2}$ and Aleksandra Kozlowska ${ }^{1}$ \\ 1 Institute of Engineering Materials and Biomaterials, Silesian University of Technology, \\ 18A Konarskiego Street, 44-100 Gliwice, Poland; aleksandra.kozlowska@polsl.pl \\ 2 Opel Manufacturing Poland Sp. z o.o., Purchasing G5, 1 Adama Opla Street, 44-121 Gliwice, Poland; \\ andrzej.kilarski@opel.com \\ * Correspondence: adam.grajcar@polsl.pl; Tel.: +48-32-2372-933
}

Received: 18 October 2018; Accepted: 7 November 2018; Published: 9 November 2018

\begin{abstract}
Detailed studies on microstructure-property relationships of thermomechanically processed medium-Mn steels with various manganese contents were carried out. Microscopic techniques of different resolution (LM, SEM, TEM) and X-Ray diffraction methods were applied. Static tensile tests were performed to characterize mechanical properties of the investigated steels and to determine the tendency of retained austenite to strain-induced martensitic transformation. Obtained results allowed to characterize the microstructural aspects of strain-induced martensitic transformation and its effect on the mechanical properties. It was found that the mechanical stability of retained austenite depends significantly on the manganese content. An increase in manganese content from $3.3 \%$ to $4.7 \%$ has a significant impact on the microstructure, stability of $\gamma$ phase and mechanical properties of the investigated steels. The initial amount of retained austenite was higher for the $3 \mathrm{Mn}-1.5 \mathrm{Al}$ steel in comparison to $5 \mathrm{Mn}-1.5 \% \mathrm{Al}$ steel $-17 \%$ and $11 \%$, respectively. The mechanical stability of retained austenite is significantly affected by the morphology of this phase.
\end{abstract}

Keywords: medium Mn steel; bainitic steel; retained austenite; thermomechanical processing; strain-induced martensitic transformation

\section{Introduction}

A microstructure consisting of ferrite, bainite and retained austenite typical for the first generation AHSSs (Advanced High-Strength Steel) is characterized by a large difference in hardness between ferrite and martensite formed as a result of strain-induced transformation. The hardness difference can be reduced by ferrite strengthening, using thermomechanical treatment or precipitation strengthening [1,2]. An alternative solution is to replace the ferrite matrix by bainite [3]. This can be done by an increase in steel hardenability. Mn and Mo additions are very effective since they affect the decomposition of the undercooled austenite significantly [1,4]. The microstructure consisting of bainite and retained austenite allows to reduce the hardness difference between microstructural components, which results in much better edge formability, stretch flangeability and mechanical properties [5-7].

Multiphase steels can be obtained as cold-rolled or thermomechnically processed. The thermomechanical processing (TMP) has the potential in energy saving and high productivity; thus, it can eliminate the need for further heat treatment. The critical factors of the TMP applied for the multiphase steels are rolling conditions and controlled cooling profiles. Kaijalainen et al. [1] reported that an increase in the total reduction in the non-recrystallization region in conjunction with a lowering of the finishing rolling temperature and microalloying with niobium increased the austenite pancaking. In this 
case, the phase transformation kinetics depends significantly on the austenite deformation degree [5,8,9]. In case of the first generation AHSSs, the main advantage of the TMP is the ability to refine the ferrite grain size by controlling the austenite pancaking $[10,11]$. Moreover, the thermomechanical treatment can increase the amount of retained austenite to obtain the optimal TRIP (TRansformation Induced Plasticity) effect $[12,13]$. In case of medium manganese steels (third generation AHSS), the TMP is also a good alternative for the cold-rolling process [14-16]. However, most publications on medium-Mn steels concern the cold-rolling process and subsequent inter-critical heat treatment.

Cold-rolled medium-Mn TRIP steels are susceptible to plastic instabilities associated with dynamic strain aging (DSA) and serrated flow (PLC-Portevin-Le Chatelier) effects due to the heat treatment required after cold-rolling. From a technological point of view, the PLC and DSA effects must be avoided. The DSA phenomenon gives rise to non-homogeneous plastic flow during the sheet-forming processes and may lead to surface defects on formed parts [17-19]. Our previous reports on thermomechanically processed medium-Mn sheet steels indicate that the problem can be avoided [7].

Newly developed fine-grained ferrite-austenite or bainitie-austenite steels contain manganese in a range of $3-12 \%$, while carbon content is ca. $0.1-0.2 \%$. These steels contain also aluminum and silicon (1-3\%) additions which delay the carbides formation during the bainitic transformation. The increased Mn amount leads to obtain the high fraction of retained austenite ( 10-30\%). The Mn addition also increases the carbon solubility and lowers the cementite precipitation temperature [20-22]. $\mathrm{Al}$ is added to partially replace silicon due to the problems related to galvanizing, hot-rolling and welding [23-25]. However, Girault et al. [26] reported that the complete removal of silicon from the chemical composition causes a decrease of strength properties. Kucerova et al. [27] investigated the effect of the Al addition in thermomechanically processed C-Mn-Si-Nb and C-Mn-Si-Al-Nb TRIP steels. They reported that the higher amount of retained austenite was formed in aluminum-alloyed steel compared to the aluminum-free steel for the same processing conditions. The final microstructures achieved slightly higher elongation at comparable ultimate tensile strength. Al and Mn additions affect the mechanical stability of retained austenite too. Kaar et al. [28] reported that too high aluminum and manganese contents deteriorate the plasticity of the TRIP steels. Mo can be also added to increase strength by its strong solid solution effect. Moreover, this element affects significantly the austenite decomposition upon cooling and is known as the one, which improves toughness [29,30].

Taking into account the increasing interest in medium manganese steels with retained austenite related to their potential application in the automotive industry, the present work focuses on the microstructure-property relationships in thermomechanically processed medium-Mn steels with a high $\mathrm{Al}$ content.

\section{Materials and Experimental Methods}

\subsection{Chemical Composition}

The investigations were carried out on two Mn-Al-Mo type steels. Chemical compositions of the investigated steels are listed in Table 1 . Both steels are characterized by the low amount of gases, $S$ and P. The chemical compositions of both steels are comparable, except of Mn addition. The contents of this element are ca. 3\% and 5\%, respectively. In order to prevent carbide precipitation, the concept with a higher aluminum content $(\sim 1.5 \%)$ and Mo addition was applied [29]. Mo was added for solid solution strengthening and to enhance producing bainite-like microstructures [31-33].

In view of weldability [23,24], the carbon content is limited to $0.17 \%$. Lun et al. [34] reported that the steel $0.15 \mathrm{C}-10 \mathrm{Mn}-1.5 \mathrm{Al}$ containing similar $\mathrm{C}$ and $\mathrm{Al}$ contents (as our steels) is weldable. However, the conventional parameters, which describe steel weldability (like carbon equivalent $C_{E}$ ), have a limited application for medium-Mn steels because they were developed for steels with an Mn content below $\sim 2 \%$ [35]. Manganese is an austenite stabilizer; it also significantly reduces the $M_{\mathrm{s}}$ temperature. Aluminum addition causes the opposite effect, i.e., it increases the $M_{\mathrm{S}}$ temperature, which results in lowering the thermodynamic stability of $\gamma$ phase [20]. 
Table 1. Chemical composition of investigated steels in wt.\%.

\begin{tabular}{cccccccccc}
\hline Steel Type & $\mathbf{C} \%$ & $\mathbf{M n} \%$ & $\mathbf{A l} \%$ & $\mathbf{S i} \%$ & $\mathbf{M o} \%$ & $\mathbf{S} \%$ & $\mathbf{P} \%$ & $\mathbf{O} \%$ & $\mathbf{N} \%$ \\
\hline 3Mn-1.5 Al & 0.17 & 3.3 & 1.7 & 0.22 & 0.23 & 0.014 & 0.010 & 0.0004 & 0.0043 \\
$5 \mathrm{Mn}-1.5 \mathrm{Al}$ & 0.16 & 4.7 & 1.6 & 0.22 & 0.20 & 0.004 & 0.008 & 0.0004 & 0.0039 \\
\hline
\end{tabular}

\subsection{Processing}

The investigated steels were melted in a Balzers VSG-50 vacuum induction furnace (Balzers, Asslar, Germany) under argon atmosphere. After melting and casting, the ingots were hot forged in a temperature range between 1200 to $900{ }^{\circ} \mathrm{C}$. Then, they were rolled in four passes to a thickness of $9 \mathrm{~mm}$. The samples $9 \times 170 \times 500 \mathrm{~mm}^{3}$ were used in a further thermomechanical process. The TMP included rolling of steel sheets in three passes to a final thickness of $4.5 \mathrm{~mm}$ obtained at $850{ }^{\circ} \mathrm{C}$. After the thermomechanical rolling, the steel sheets were subjected to controlled cooling. Figure 1 shows the cooling route of the investigated steels. In case of 3Mn-1.5Al (Figure 1a), the steel sheets after the thermomechanical rolling were slowly cooled to $700{ }^{\circ} \mathrm{C}$ to induce to some extent the austenite-ferrite transformation. In the next step, the steel sheets were cooled quickly $\left(\sim 27^{\circ} \mathrm{C} / \mathrm{s}\right)$ to isothermal holding temperature of $400{ }^{\circ} \mathrm{C}$ and annealed at this temperature for $300 \mathrm{~s}$. Finally, the sheet specimens were air cooled to room temperature. $5 \mathrm{Mn}-1.5 \mathrm{Al}$ steel sheets were cooled continuously from the finish rolling temperature to $400{ }^{\circ} \mathrm{C}$ (Figure $1 \mathrm{~b}$ ) to realize the bainitic transformation step. The last stage included cooling in air to room temperature.

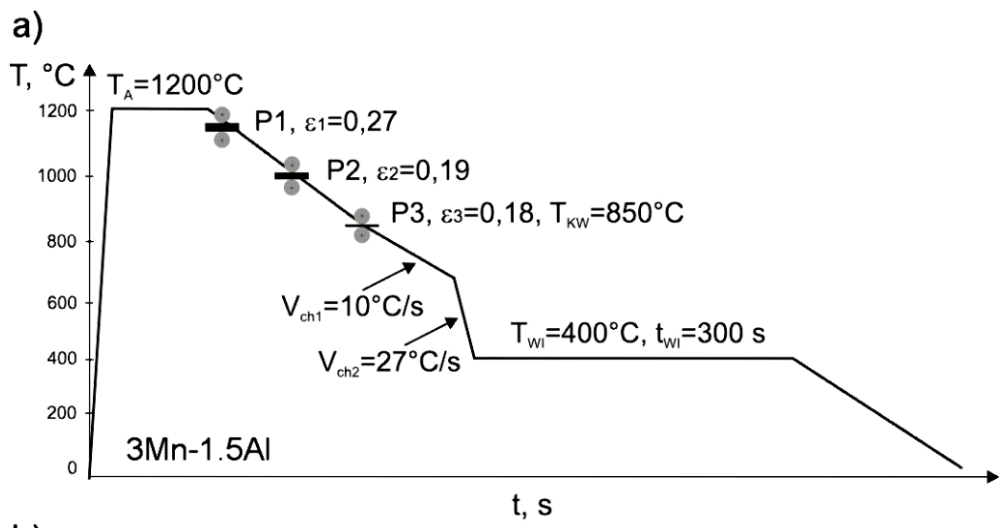

b)

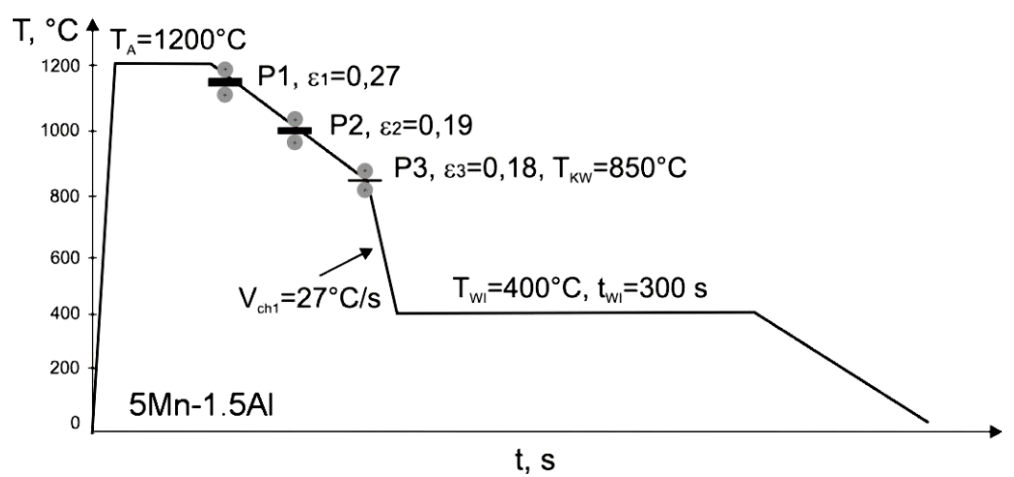

Figure 1. Parameters of thermomechanical processing of (a) $3 \mathrm{Mn}-1.5 \mathrm{Al}$ steel and (b) $5 \mathrm{Mn}-1.5 \mathrm{Al}$ steel ( $T_{\mathrm{KW}}$-finish rolling temperature).

\subsection{Static Tensile Tests}

Room temperature uniaxial tensile tests were performed on steel samples ( $4.5 \mathrm{~mm}$ thick) machined from the thermomechanically rolled sheets along the rolling direction. The tensile tests were carried out using a Zwick Z/100 universal testing machine (Zwick/Roell, Ulm, Germany). Tests were performed 
up to rupture. Mechanical properties were determined based on the average values of 3 tests for each steel. The tensile tests were performed to determine the mechanical properties of the investigated steels and also to observe the microstructure changes related to strain-induced martensitic transformation of the retained austenite.

\subsection{Microstructure Examination}

The microstructural examinations were carried out using light microscopy (LM), scanning electron microscopy (SEM) and transmission electron microscopy (TEM). Two types of samples were prepared:

- at the initial state (thermomechanically rolled),

- deformed in the static tensile test.

Specimens for optical and SEM observations were prepared according to the direction of hot-rolling (initial state) and along the direction of tensile load. Both types of the specimens were mechanically ground with $\mathrm{SiC}$ paper up to 1500 grid, then they were polished with a diamond paste. Steel samples for optical observations were etched in 10\% aqueous sodium metabisulfite solution, whereas specimens for SEM observation were etched in 5\% Nital.

The observations were performed using a Leica MEF 4A optical microscope (Leica, Wetzlar, Germany). Microstructural details were revealed by using Zeiss SUPRA 25 (SEM) microscope operating at $20 \mathrm{kV}$ (Carl Zeiss AG, Jena, Germany), working in a backscattered electron (BSE) detection mode. Transmission electron microscopy (TEM) studies were conducted using the Titan 80-300 FEI transmission electron microscope (FEI, Hillsboro, OR, USA). TEM lamellas were prepared using FIB-Focused Ion Beam method (Quanta 3D 200i, FEI, Hillsboro, OR, USA). The following observation techniques were applied: bright field (BF), dark field (DF) and selected area diffraction (SAD). A convergent beam electron diffraction (CBED) was done using the following parameters: nominal spot size -6 and the divergence angle $-12^{\circ}$. The focus of the beam on a selected component of the structure was used, which was particularly important for the identification of retained austenite and TRIP effect.

The X-ray diffraction (XRD) was carried out on the steel specimens at the initial state (thermomechanically rolled) and after static tensile tests. The measurements were done using the $X^{\prime}$ Pert PRO diffractometer (PANalytical, Malvern, UK) with cobalt radiation operating at $40 \mathrm{kV}, 30 \mathrm{~mA}$ and a graphite monochromator on a diffracted beam. The phase identification was performed according to the data from International Centre for Diffraction Data ICDD (PDF-4+ 2016, International Centre for Diffraction Data ICDD, Newtown Square, CT, USA). In order to determine the volume fraction of retained austenite, the methodology proposed by Muruyama [36] was applied. The volume fraction of retained austenite was calculated based on total intensity of peaks: (200)Fe $\mathrm{Fe}_{\alpha},(211) \mathrm{Fe}_{\alpha},(200) \mathrm{Fe}_{\gamma}$, (220) $\mathrm{Fe}_{\gamma}$ and (311) $\mathrm{Fe}_{\gamma}$. Based on X-ray diffraction patterns, a lattice parameter of $\gamma$ phase was specified (Equation (1)) [37]. It was necessary to determine the carbon content in the austenite.

$$
a_{\gamma}=3.556+0.0453 \mathrm{C}_{\gamma}+0.00095 \mathrm{Mn}+0.0056 \mathrm{Al}
$$

where: $a_{\gamma}$-lattice parameter of the austenite $(\AA), C_{\gamma}, M n, A l — c a r b o n$, manganese, aluminum contents in the austenite (wt.\%), respectively.

\section{Results}

\subsection{Initial Microstructures}

Microstructural observations show that the Mn content affects the microstructure of the investigated steels (Figure 2). It is interesting since the difference in manganese content between two steels is only $1.4 \mathrm{wt} . \%$. Both steels are characterized by fine lath-type microstructures. However, it can be seen that the phase transformations upon cooling took place from the austenite with a relatively large grains (a size of individual austenite grains $>20 \mu \mathrm{m}$ ). In 3Mn-1.5Al steel, several bainitic packets are formed as part of 
one grain of the prior austenite (Figure 2a). Etching the samples in the aqueous sodium metabisulfite solution reveals light grains of retained austenite, which usually are located along the direction of bainitic lath growth. Retained austenite is uniformly distributed in the bainitic matrix. The fraction of polygonal ferrite obtained as a result of slow cooling in the $\gamma \rightarrow \alpha$ transformation range is incidental. It indicates that the tested steels are characterized by high hardenability and they show the low tendency to form polygonal ferrite. Moreover, the areas consisting of blocky-type grains are visible.

The thermal instability of larger blocky grains of $\gamma$ phase was revealed using SEM observations. The thermal stability to room temperature is shown only by the layered areas of retained austenite located between the bainitic ferrite laths (Figure 2b). Blocky-type grains were partially transformed into martensite during the final cooling of the steel sheets to room temperature. These grains are usually characterized by a lower carbon content (higher $M_{\mathrm{s}}$ temperature) [11,12] than layers located between the bainitic ferrite laths. These bainite laths additionally exert a hydrostatic pressure stabilizing the $\gamma$ phase [38-40]. The result of the blocky-grains partial transformation is the occurrence of numerous martensite-austenite (MA) areas in the steel microstructure.

The amount of retained austenite in $5 \mathrm{Mn}-1.5 \mathrm{Al}$ steel is significantly smaller (Figure $2 \mathrm{c}$ ) than in the steel containing the lower Mn content. In the present case, only thin layers of the $\gamma$ phase were stable at room temperature. Thicker layers and blocky grains located at the boundaries of bainitic packets were partially transformed to martensite and formed MA constituents (Figure 2d).

a)

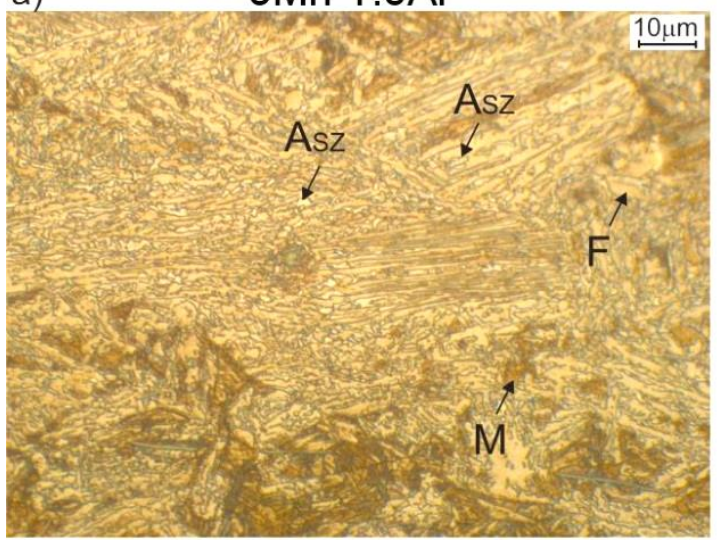

b)

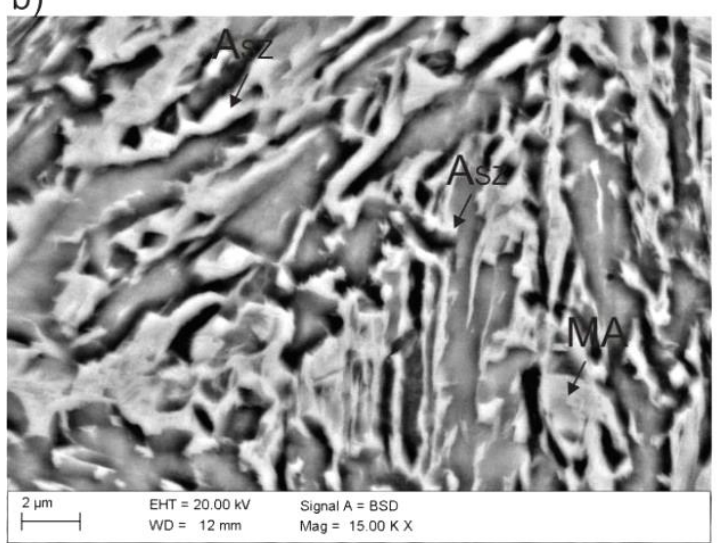

c)

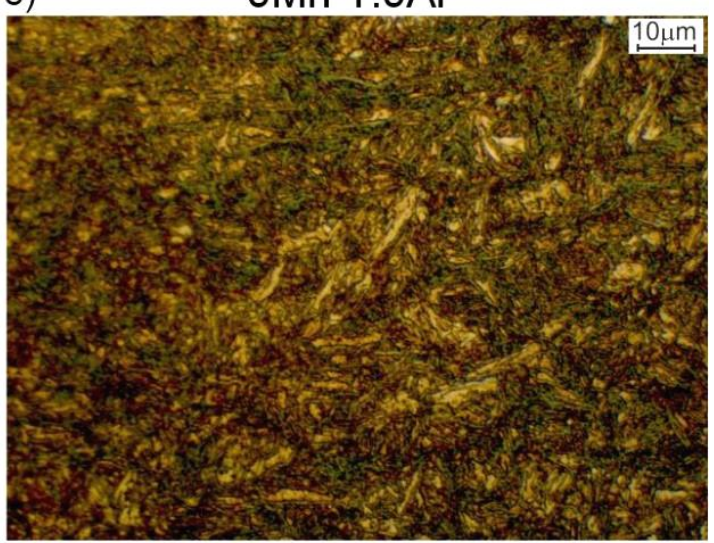

d)

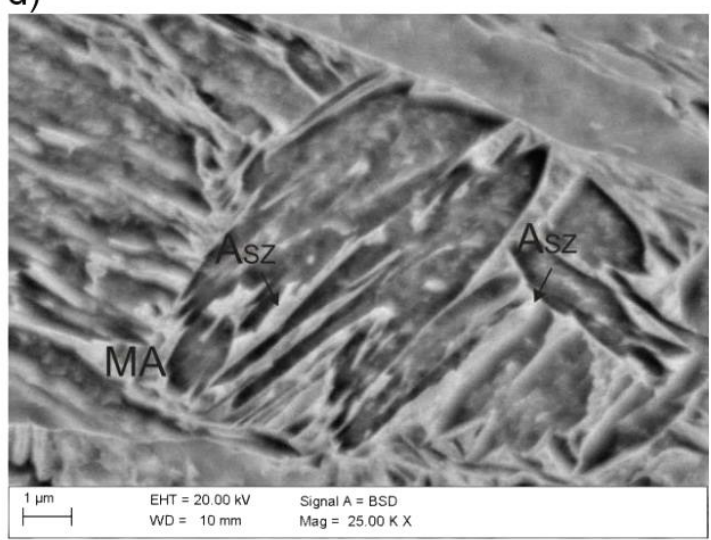

Figure 2. Bainitic microstructures with retained austenite and martensitic-austenitic constituents (a,b) 3Mn-1.5Al steel, (c,d) 5Mn-1.5Al steel; F-ferrite, M-martensite, MA-martensite-austenite constituents, $\mathrm{A}_{\mathrm{SZ}}$-retained austenite.

In case of $5 \mathrm{Mn}-1.5 \mathrm{Al}$ steel, the dual nature of bainitic laths was characteristic. Besides thin bainitic laths (Figure 2d), elongated bainitic ferrite laths characterized by a high thickness were observed. 
Moreover, small particles (areas) characterized of a various size were located inside the bainitic ferrite laths. Similar microstructures were observed by Caballero et al. [41] in bainitic steels. According to a theory presented in their work [40] on bainitic steels with retained austenite, thin laths of bainitic ferrite were formed in the initial stage of the bainite transformation. Due to diffusion, the excess carbon content located between the ferrite laths formed austenitic films during the bainitic transformation. It is related to the inhibitory interaction of $\mathrm{Si}$ and/or $\mathrm{Al}$ for the cementite precipitation. As the transformation time is extended, the continuous austenite laths are decomposed forming isolated austenite islands. In the case of steels characterized by low $\mathrm{Si}$ and $\mathrm{Al}$ contents, the austenite decomposes into separated carbides. Next, single bainitic ferrite laths combine into larger areas as shown in Figure 2d. During the final cooling of the steel to room temperature, austenite areas characterized by the lower stability transformed partially to martensite. As a result, they form martensitic-austenitic (MA) particles located inside the thick bainitic ferrite laths. In addition to the MA islands, carbides are also often formed which deteriorate the impact toughness.

Observations performed using TEM confirmed the presence of retained austenite in the investigated steels. For the steel with a higher manganese content, the $\gamma$ phase layers located between the bainitic ferrite were stable (Figure 3a). The location of retained austenite using the dark field technique was revealed (Figure 3b). The microdiffraction from the middle of the $\gamma$ phase lath is shown in Figure 3c. It is important that laths with a thickness below $0.2 \mu \mathrm{m}$ were stable, while thicker laths were subjected to a partial martensitic transformation forming MA constituents.
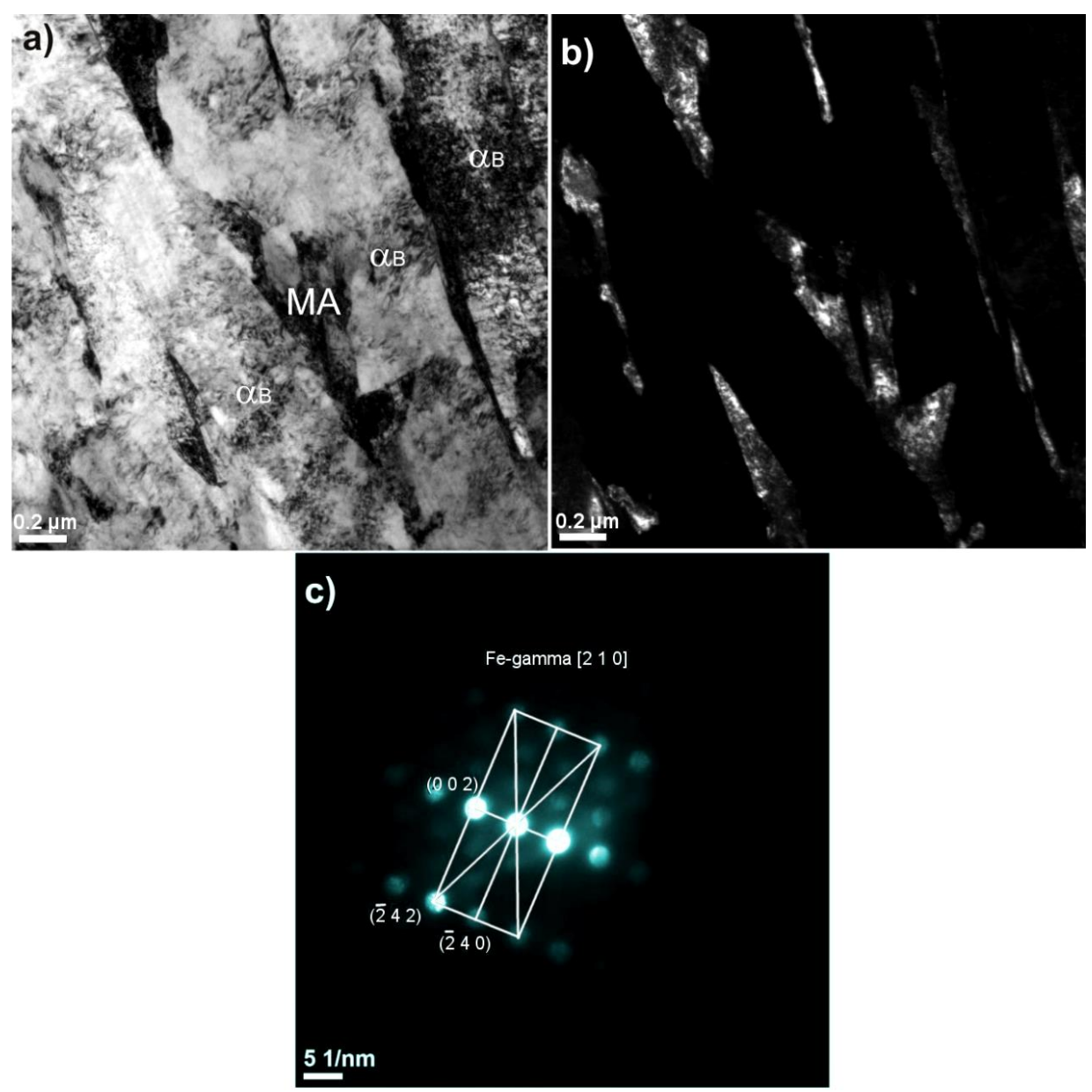

Figure 3. Retained austenite layers located between bainitic ferrite laths in $5 \mathrm{Mn}-1.5 \mathrm{Al}$ steel (a) bright field, (b) dark field from (002) $\mathrm{Fe}_{\gamma}$, (c) microdiffraction solution from the middle of the austenite lath; $\alpha_{\mathrm{B}}$-bainitic ferrite, MA-martensite-austenite constituent. 
The presence of retained austenite and martensitic-austenitic areas was also confirmed in the steel characterized by the lower Mn content (Figure 4). The location of retained austenite is shown in Figure 4b. It can be seen that the austenite layers are less regularly oriented and have a more blocky-type shape. Grains with a size of about $0.5-\mu \mathrm{m}$ were subjected to partial martensitic transformation and they occur as MA type islands. Both investigated steels are characterized by a bainitic ferrite matrix with a high dislocation density (Figures 3 and 4), which is a consequence of the low finishing rolling temperature.
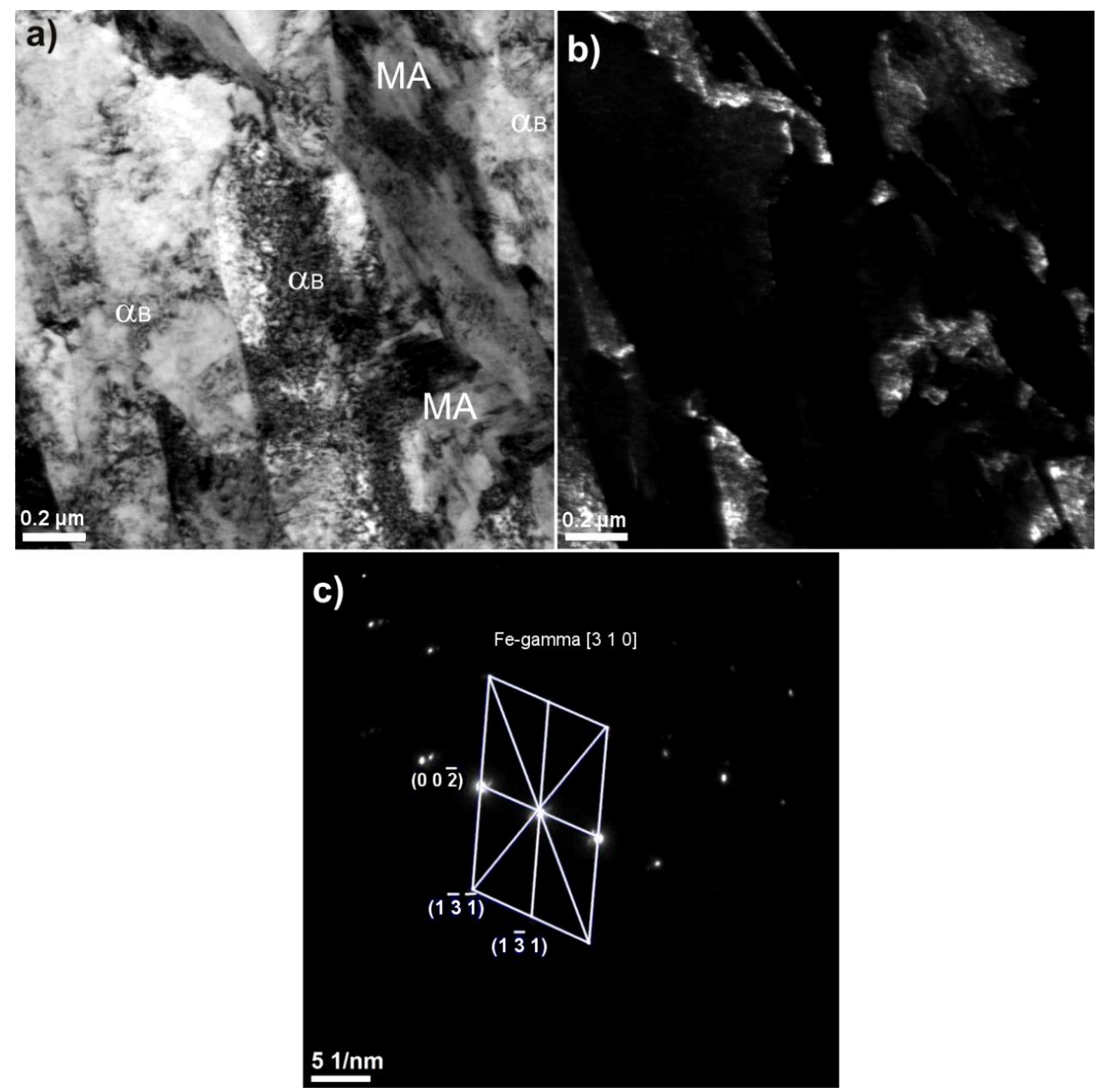

Figure 4. Austenite layers and blocky-type MA grains in bainitic ferrite in 3Mn-1.5Al steel (a) bright field, (b) dark field from $(00 \overline{2}) \mathrm{Fe}_{\gamma}$, (c) SAD (Selection Area Diffraction) solution from the lower austenite lath; $\alpha_{B}$-bainitic ferrite, MA—martensite-austenite constituent.

\subsection{XRD Analysis}

In order to identify the phase composition of the tested steels at the initial state and after tensile tests, qualitative $X$-ray analysis was performed. Figure $5 a, b$ shows $X$-ray diffraction patterns for the thermomechanically rolled $3 \mathrm{Mn}-1.5 \mathrm{Al}$ and $5 \mathrm{Mn}-1.5 \mathrm{Al}$ steels. For both steels, three diffraction peaks from the $\mathrm{Fe}_{\alpha}$ phase and four peaks from the $\mathrm{Fe}_{\gamma}$ phase were identified. Obtained results confirmed the presence of retained austenite in the tested steels. Completing the hot-rolling at a relatively low temperature caused some texture effects in the investigated steels. The peak intensities disturbances in relation to the standard values occur both for the $\alpha$ phase and the retained austenite. The privileged crystallographic orientation reveals an increase in the intensity of (220) peaks and (002)Fe $\mathrm{Fe}_{\gamma}$, while the peak from the planes $(111) \mathrm{Fe}_{\gamma}$ almost disappeared. 

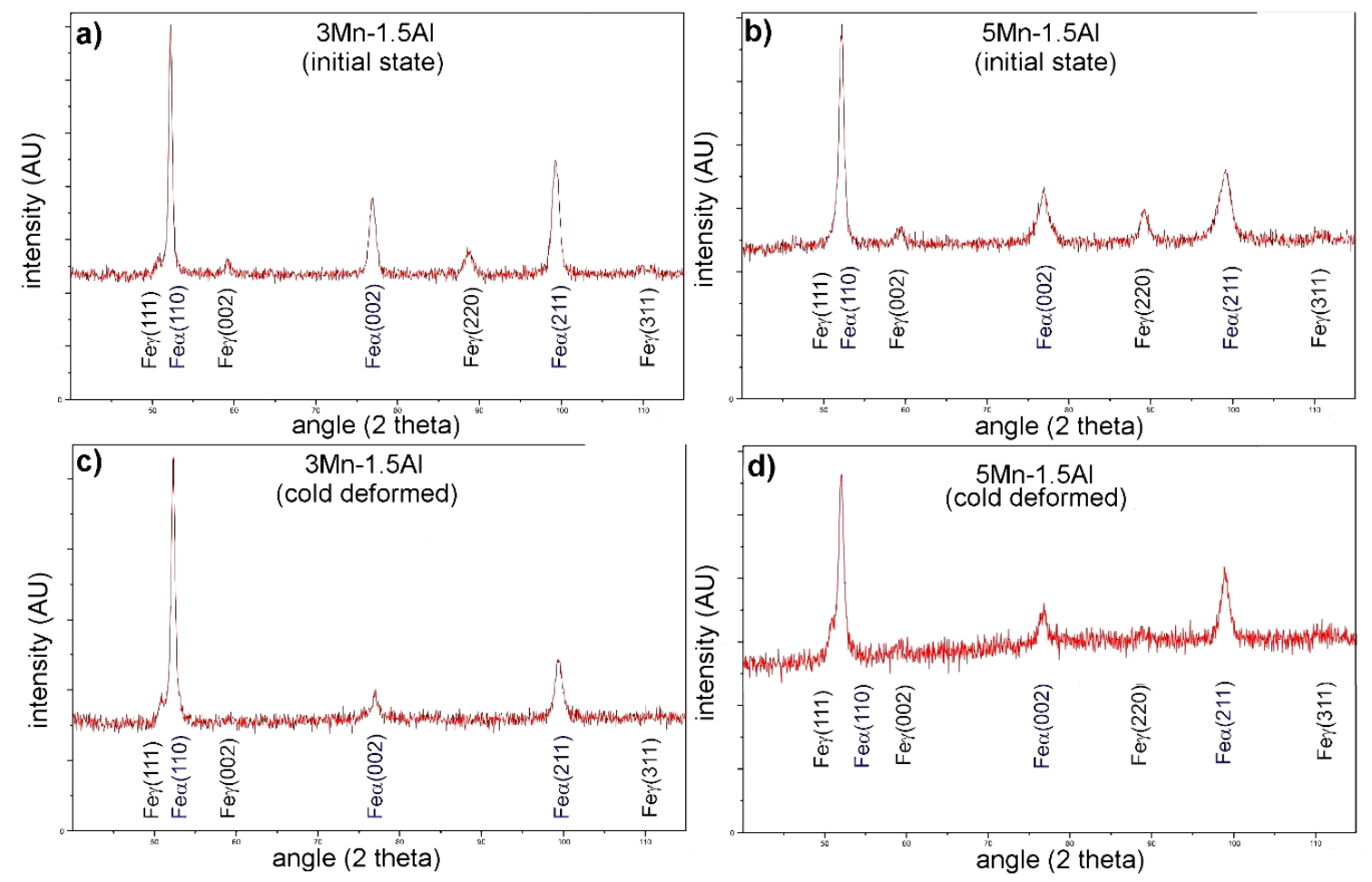

Figure 5. X-ray diffraction patterns of: (a) $3 \mathrm{Mn}-1.5 \mathrm{Al}$ steel, (b) $5 \mathrm{Mn}-1.5 \mathrm{Al}$ steel at the initial state, (c) $3 \mathrm{Mn}-1.5 \mathrm{Al}$ steel, (d) $5 \mathrm{Mn}-1.5 \mathrm{Al}$ steel after static tensile tests (cold deformed).

The amount of $\gamma$ phase in the steels at the initial state was calculated. It can be concluded that the steel containing 3\% Mn possessed a lager fraction of retained austenite than the $5 \mathrm{Mn}$ steel. It confirms the results of earlier microstructural observations (Figure 2). The amount of $\gamma$ phase was $17.3 \%$ for $3 \mathrm{Mn}-1.5 \mathrm{Al}$ steel and decreases to $10.7 \%$ for the steel with $5 \% \mathrm{Mn}$. A similar effect of the increased volume fraction of retained austenite in the steel with lower Mn content was observed in our previous studies [42], in which the finish rolling temperature was reduced to $750{ }^{\circ} \mathrm{C}$. Based on the Equation (1), the carbon concentration in the retained austenite was calculated. The carbon content in the retained austenite was higher in the $3 \mathrm{Mn}-1.5 \mathrm{Al}$ steel (1.11\%). As the Mn content increases, the carbon enrichment of the $\gamma$ phase decreases to $0.94 \%$.

X-ray diffraction patterns of the samples after static tensile tests are shown in Figure $5 \mathrm{c}$,d. An evident decrease in the amount of retained austenite for both investigated steels can be observed. On the one hand, the disappearance of diffraction peaks from (200), (220) and (311) $\mathrm{Fe}_{\gamma}$ planes was observed. On the other hand, the (111) $\mathrm{Fe}_{\gamma}$ peaks were identified. It indicates that some fraction of retained austenite did not transform during cold deformation. The reduction of the peak quantities and their intensity confirm the occurrence of the TRIP effect.

\subsection{Mechanical Properties and Stability of Retained Austenite}

\subsubsection{Mechanical Properties}

Mechanical properties determined in a static tensile test are presented in Figure 6. Tensile tests showed that the increase in manganese content from 3.3\% to $4.7 \%$ leads to different mechanical properties. One can observe a significant difference in strength (UTS, YS) and plastic properties (TE and UE). With increasing Mn content, yield strength increases from 700 to $882 \mathrm{MPa}$ while the difference in tensile strength was around $260 \mathrm{MPa}$. A calculated YS/UTS ratio ca. 0.73 confirmed that both investigated steels show high work strengthening after yielding. 


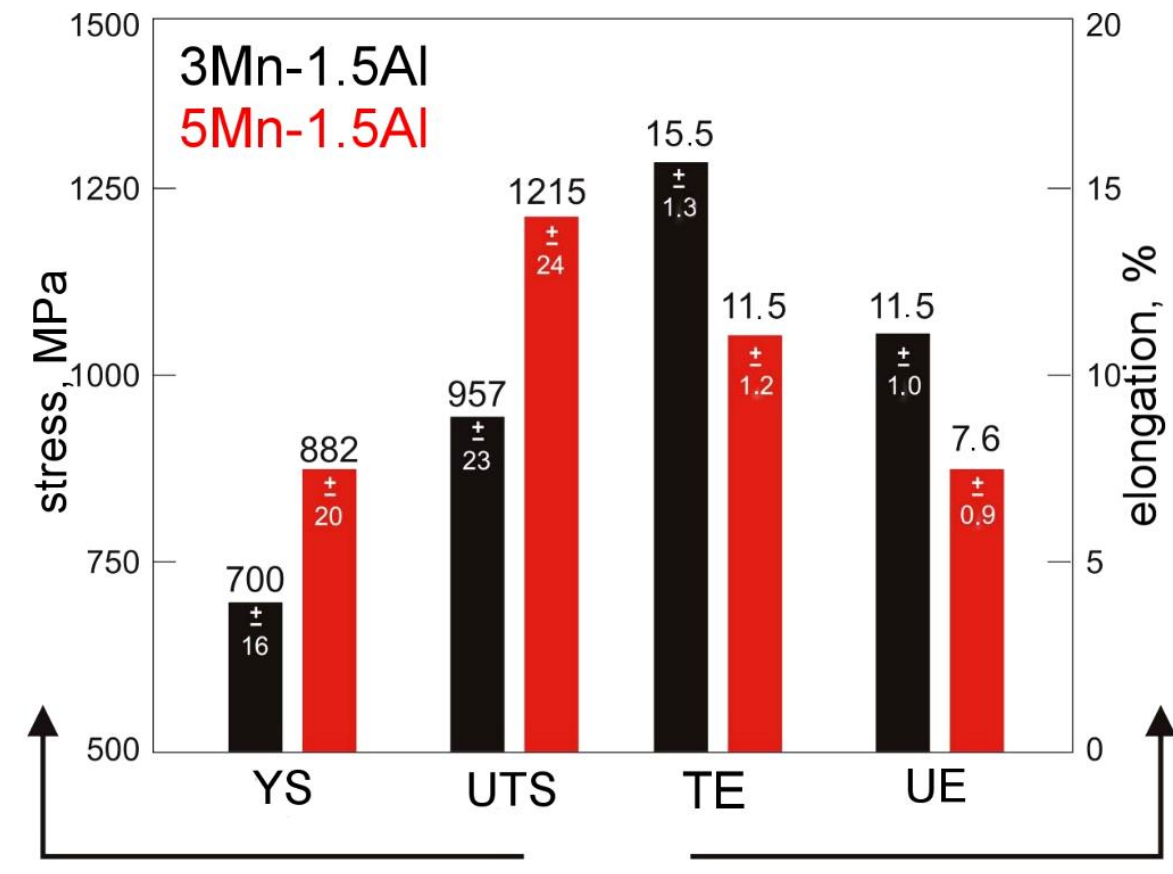

\begin{tabular}{|l|c|c|c|}
\hline & YS/UTS & UE/TE & $\begin{array}{l}\text { UTS } \times \text { TE, } \\
\text { MPa } x \%\end{array}$ \\
\hline $3 \mathrm{Mn}-1.5 \mathrm{Al}$ & 0.73 & 0.74 & 14849 \\
\hline $5 \mathrm{Mn}-1.5 \mathrm{Al}$ & 0.72 & 0.66 & 13972 \\
\hline
\end{tabular}

Figure 6. Mechanical properties of investigated steels determined in static tensile tests.

A UTS value depends on the ability of steel to strain hardening. The values of uniform elongation, which are $11.5 \%$ and $7.6 \%$, respectively for $3 \mathrm{Mn}-1.5 \mathrm{Al}$ and $5 \mathrm{Mn}-1.5 \mathrm{Al}$ steels (Figure 6) depend also on the strain hardening rate. Kaar et al. [28] reported that too high aluminum and manganese contents deteriorate the plasticity of the TRIP steels at increased strengths. Considering the UE/TE ratios which are 0.74 and 0.66 for the steels of lower and higher Mn contents respectively, it can be concluded that $3 \mathrm{Mn}-1.5 \mathrm{Al}$ steel is more susceptible to uniform straining. Total elongation values were relatively good $(15.5 \%$ and $11.5 \%)$. The curves showing true stress vs. true strain and work hardening exponent vs. true strain are presented in Figure 7a,b. Based on the obtained results (Figure 7b), it can be concluded that the steel with lower Mn content shows a better tendency to more gradual strain hardening. The shape of the curves indicate that the highest work hardening rate is limited to the initial stage of strain, i.e., in the range of true strain of up to $\sim 0.04$. The value of the work hardening exponent increases rapidly to $\sim 0.18$ and $0.1-$ for $3 \mathrm{Mn}-1.5 \mathrm{Al}$ and $5 \mathrm{Mn}-1.5 \mathrm{Al}$ steels, respectively. Its increase is probably related to the occurrence of the strain-induced martensitic transformation. After reaching the maximum, the $\mathrm{n}$ exponent value deteriorates rapidly for both investigated steels. It results in a smaller contribution of martensitic transformation to further strengthening of the steel. In case of the steel with a lower manganese content, a slight delay in the decrease of work hardening exponent value in the true strain range $0.06-0.09$ was observed. It may be due to more intense martensite formation, which delays necking in the $3 \mathrm{Mn}-1.5 \mathrm{Al}$ steel. 

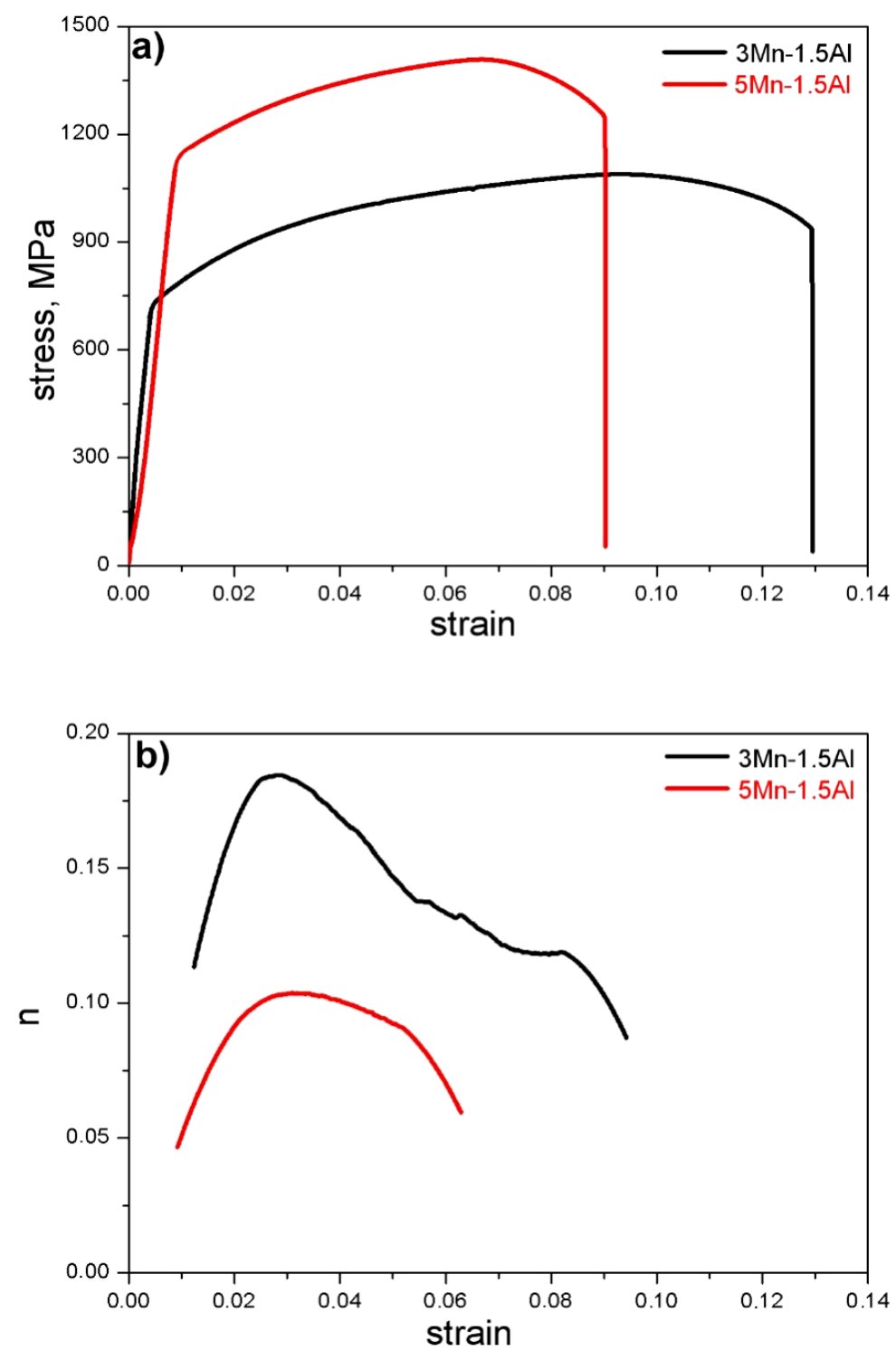

Figure 7. True stress-true strain curves of investigated steels (a) work hardening exponent as a function of true strain $(\mathbf{b})$.

\subsubsection{Mechanical Stability of Retained Austenite}

A detailed analysis of the samples deformed in the static tensile tests is crucial to determine the contribution of strain-induced martensitic transformation. The microstructure of $3 \mathrm{Mn}-1.5 \mathrm{Al}$ steel was characterized by the presence of numerous blocky-type austenitic grains which transformed into martensite during the tensile test (Figure 8). Only thin layers of the $\gamma$ phase with a thickness below $0.3 \mu \mathrm{m}$ remain stable. In case of the steel containing $5 \% \mathrm{Mn}$, the transformation also begins at the blocky grains and thicker layers of $\gamma$ phase located between the bainitic ferrite (Figure 9). Layers with a thickness below $0.3 \mu \mathrm{m}$ do not undergo martensitic transformation. 


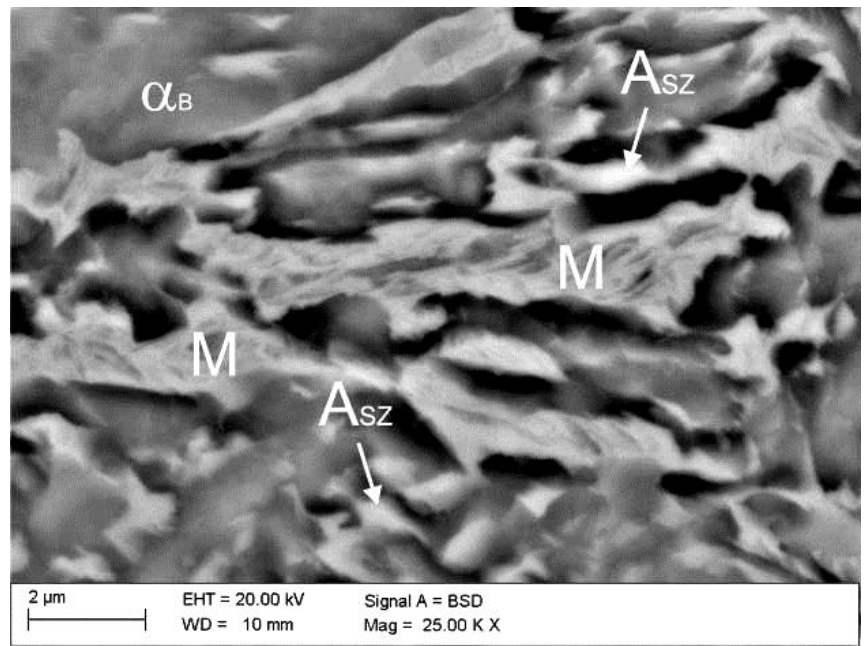

Figure 8. Microstructure of $3 \mathrm{Mn}-1.5 \mathrm{Al}$ steel after tensile test; $\alpha_{\mathrm{B}}$-bainitic ferrite, $\mathrm{M}-$ martensite, Asz-retained austenite.

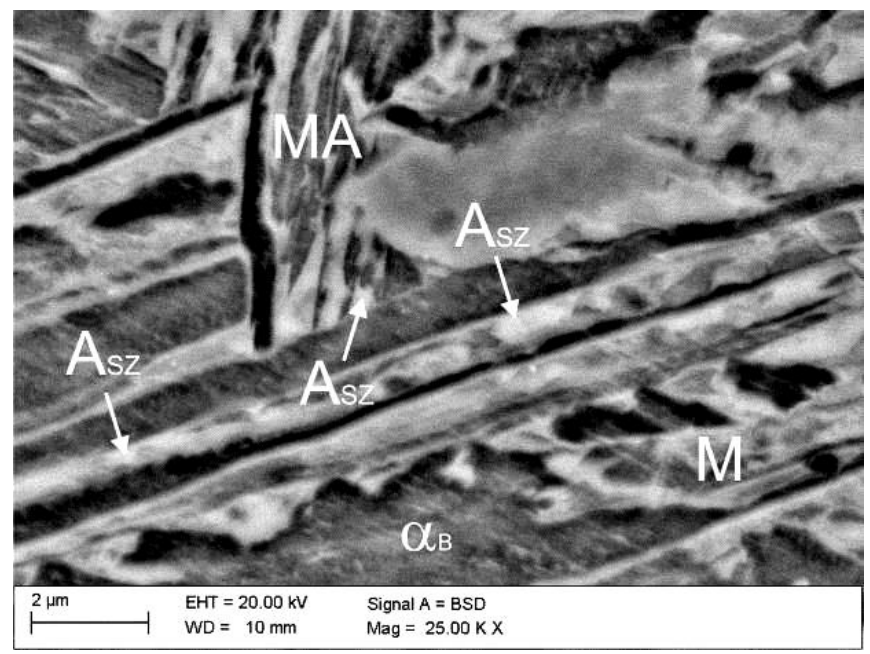

Figure 9. Microstructure of $5 \mathrm{Mn}-1.5 \mathrm{Al}$ steel after tensile test $\alpha_{\mathrm{B}}$-bainitic ferrite, $\mathrm{M}-$ martensite, MA-martensite-austenite constituents, AsZ -retained austenite.

The morphological details of the martensite formed as a result of the applied load were revealed using transmission electron microscopy. Figure 10 shows a typical blocky grain of retained austenite transformed into martensite in $3 \mathrm{Mn}-1.5 \mathrm{Al}$ steel. It can be observed that in the blocky grains, the martensitic transformation can be initiated in several places simultaneously (Figure 10), leading to grain fragmentation. The presence of retained austenite and martensite was confirmed by the dark field technique (Figure 10c,d). Martensite exhibits fine plate-like morphology. The plate thicknesses were in a range from $10 \mathrm{~nm}$ to $30 \mathrm{~nm}$ (Figure 10b,d).

Figure 10b shows the magnified martensitic area, which was confirmed by the microdiffraction in Figure 10e. Martensite observed in the steel containing 5\% Mn had also a thin-plate morphology (Figure 11). The identification of these structural constituents was done using electron diffraction, and this was illustrated using the dark field technique (Figure 11c-f). The diffraction patterns in Figures 10 and 11 show a disk-type diffraction, which is a characteristic of the convergent beam electron diffraction (CBED). Due to the lower carbon enrichment of the $\gamma$ phase compared to the $3 \mathrm{Mn}-1.5 \mathrm{Al}$ steel and the disadvantageous effect of the increasing concentration of $\mathrm{Mn}$ on the lowering the $\mathrm{Fe}_{3} \mathrm{C}$ precipitation temperature [20], fine carbide precipitates were also identified between the martensite plates (Figure 11g,h). 

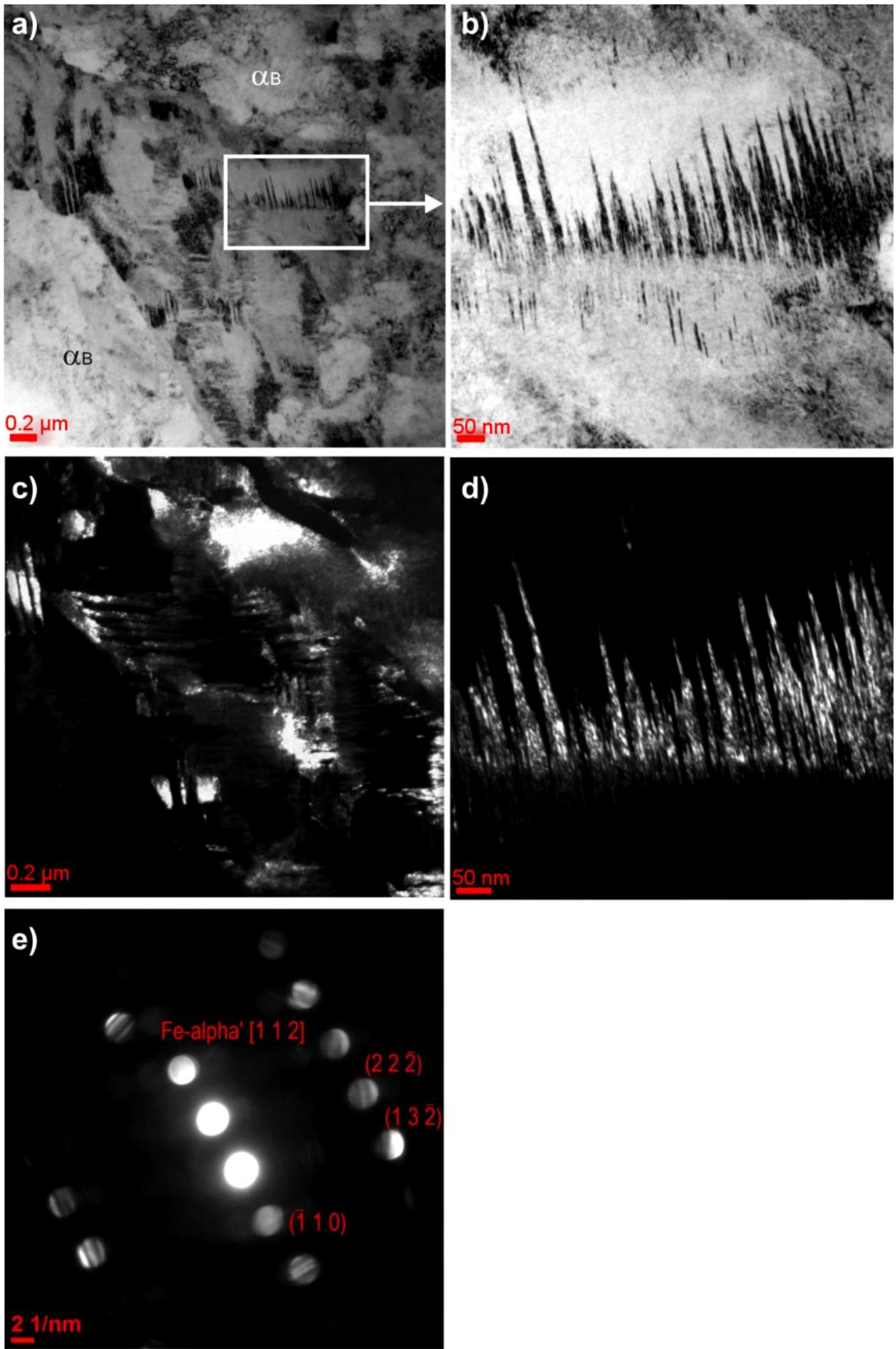

Figure 10. Blocky grain of retained austenite partially transformed into martensite in $3 \mathrm{Mn}-1.5 \mathrm{Al}$ steel (a) bright field, (b) magnification of the fragment from (a), (c) dark field from retained austenite, (d) dark field from martensite $(13 \overline{2})$, (e) microdiffraction solution from the martensitic plates area. 

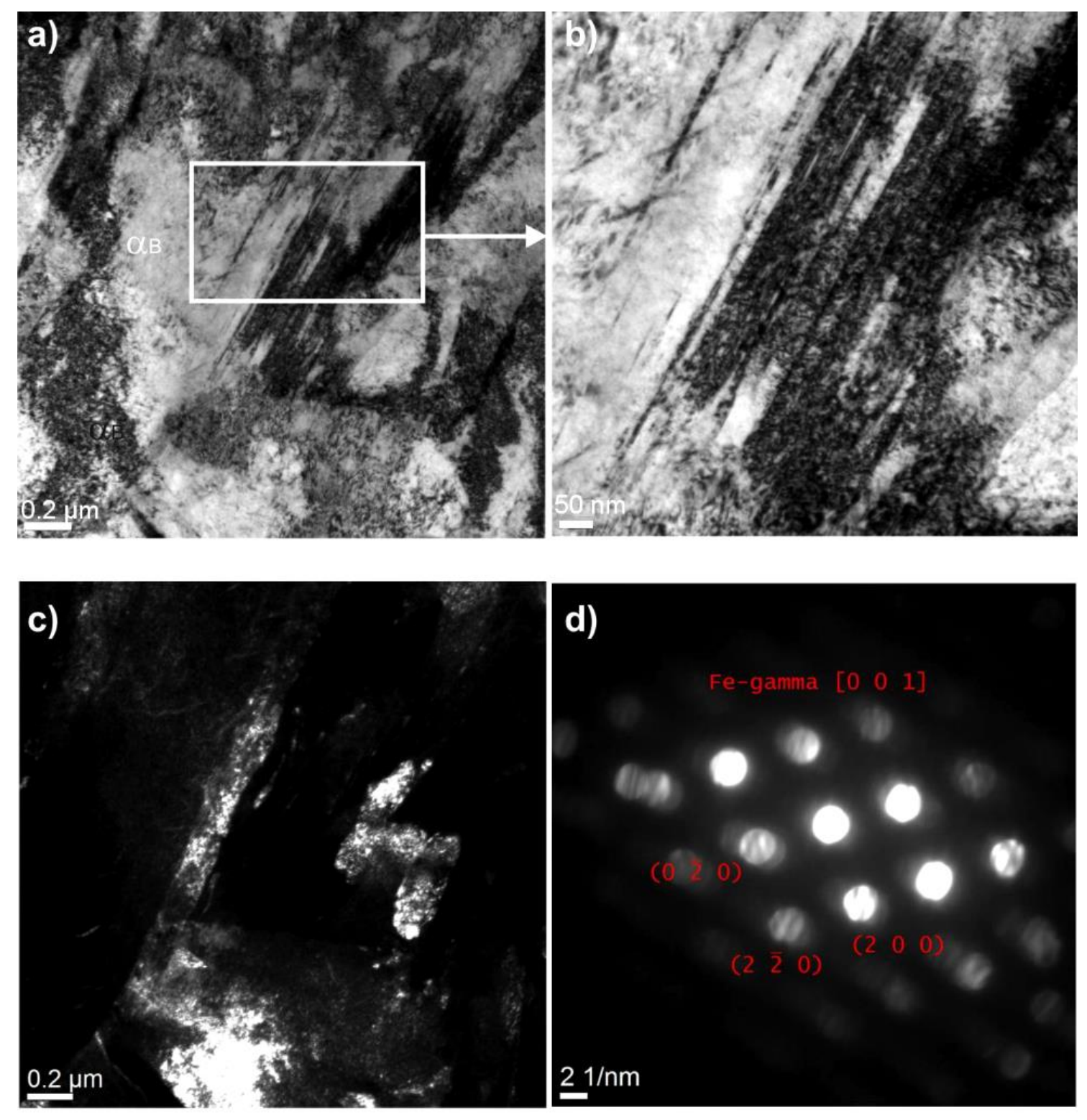

\section{d)}
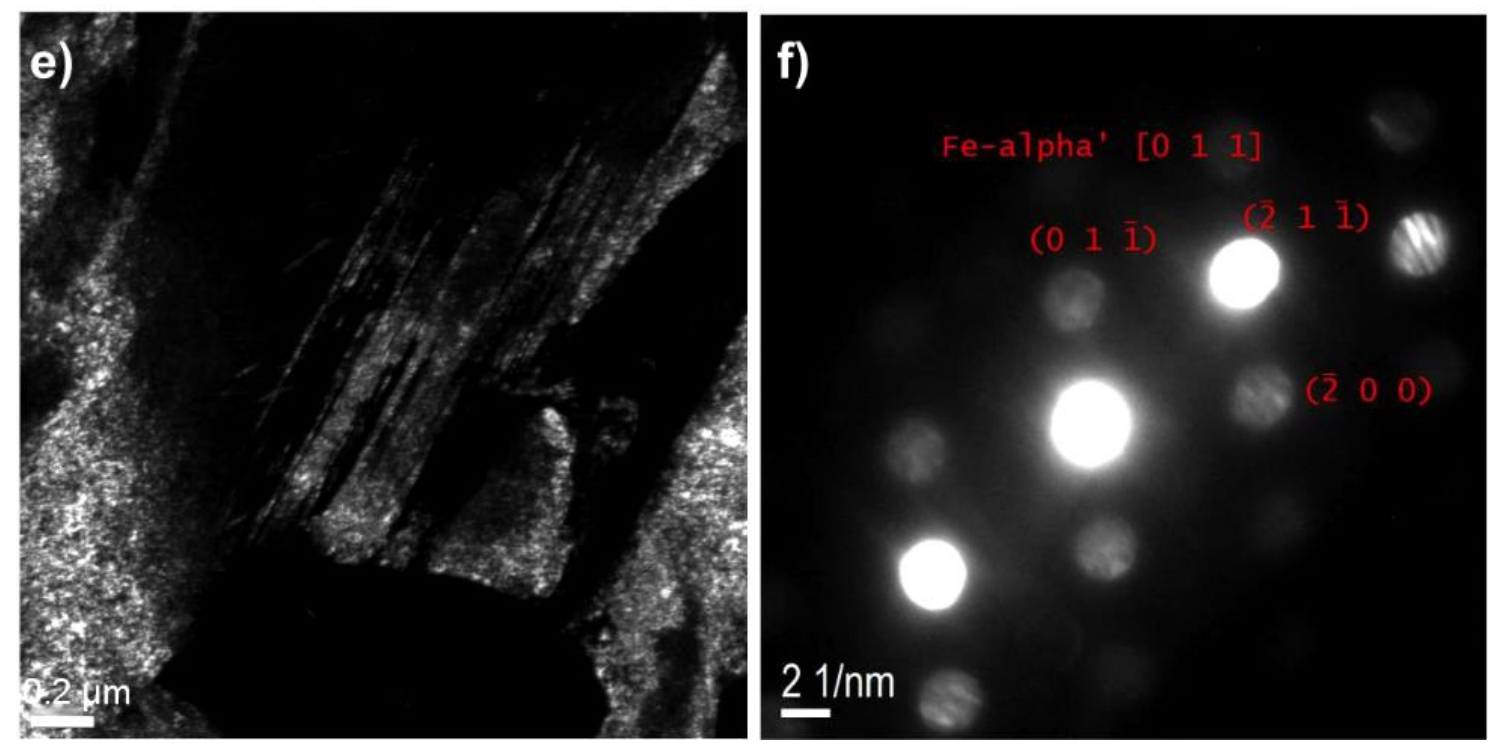

Figure 11. Cont. 

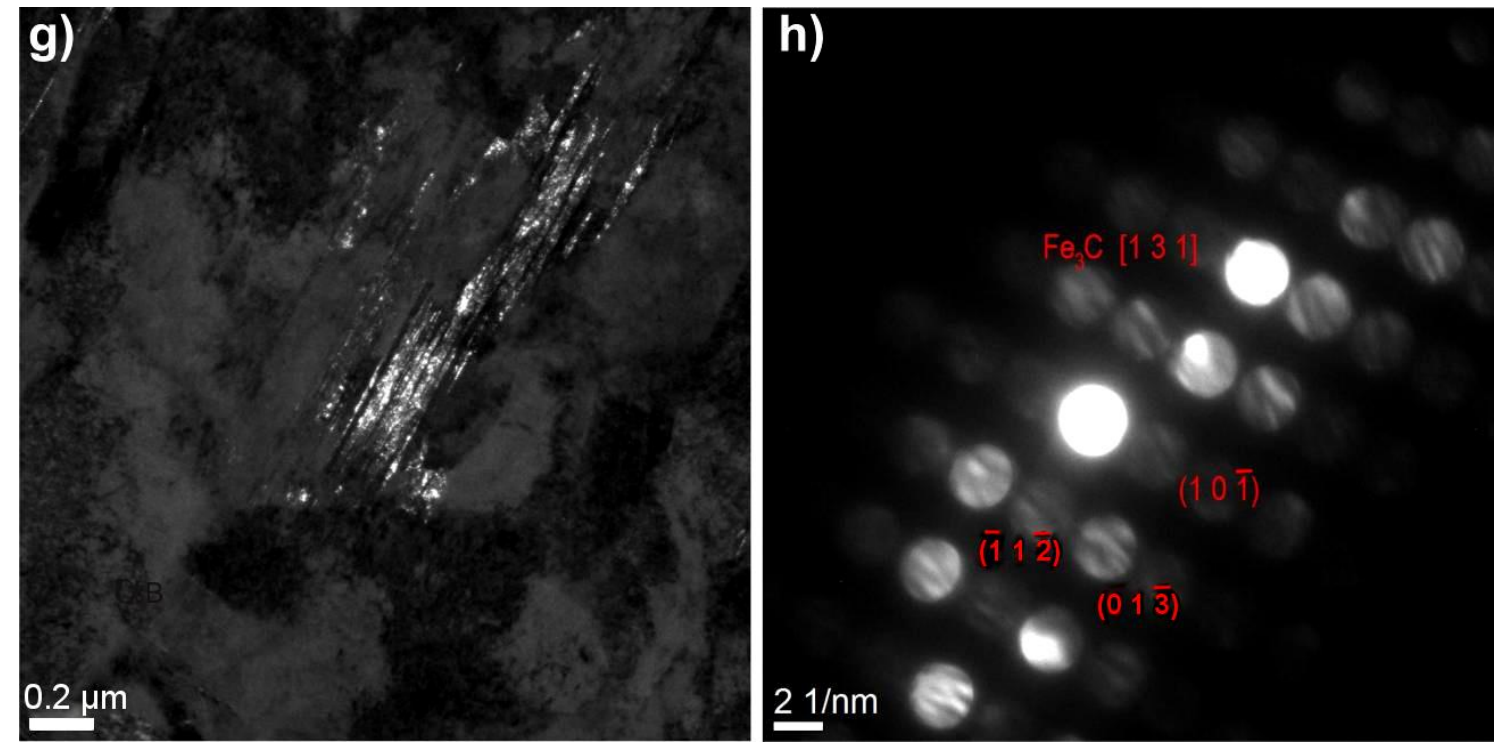

Figure 11. Plate martensite with interlath carbides located next to retained austenite and bainitic ferrite characterized by high dislocation density in $5 \mathrm{Mn}-1.5 \mathrm{Al}$ steel (a) bright field, (b) magnification of the fragment from (a), (c) dark field from the austenite reflex (200) (d), microdiffraction solution from the retained austenite lath, (e) dark filed from martensite $(\overline{2} 1 \overline{1})$, (f) microdiffraction solution from the martensitic plates area, (g) dark field from the cementite $(\overline{1} 1 \overline{2}),(\mathbf{h})$ microdiffraction solution from carbides area.

\section{Discussion}

\subsection{Effect of Chemical Composition}

The fundamental issue regarding sheet steels for the automotive industry is their weldability. This was not the aim of the current work. However, the carbon content in our steels was limited to $0.17 \%$ to avoid possible joining problems. Welding of medium-Mn steels is a new research problem. Medium-Mn steels contain some fraction of austenitic phase in a fusion zone. Lun et al. [34] reported that the laser welded $0.15 \mathrm{C}-10 \mathrm{Mn}-1.5 \mathrm{Al}$ steel achieved approximately $96 \%$ joint efficiency with respect to the base material. Since our steels have similar contents of $\mathrm{C}$ and $\mathrm{Al}$ and lower Mn contents, one can expect that they should be weldable. Steels containing a higher amount of carbon and manganese were already welded successfully [35]. However, when the manganese content increases, welding problems such as: hot cracking, coarse columnar grains and brittleness in heat affected zone can occur due to high amount of austenitic phase.

Since the two investigated steels contain similar amounts of $\mathrm{C}, \mathrm{Al}, \mathrm{Mo}$ and $\mathrm{Si}$, the major difference in microstructure and mechanical properties should be due to the difference in manganese content. The results showed that the increase in Mn content from 3.3\% to 4.7\% significantly affects the microstructure and strengthening behavior. The high Mn content increased the steel hardenability, which is further enhanced by a strong Mo effect. That is why the steels do not contain ferrite. It is very often enough to add only $0.15 \%$ Mo to obtain a similar effect [2,4]. In our case, the Mo addition was $\sim 0.2 \%$. The amount of retained austenite in $5 \mathrm{Mn}-1.5 \mathrm{Al}$ steel was significantly smaller $(\sim 11 \%)$ when compared to the steel containing $3 \% \mathrm{Mn}(\sim 17 \%)$. It was confirmed by microstructural observations and XRD analysis. It is interesting due to the fact that manganese is an austenite stabilizer. However, the experimental results obtained by other authors [43-45] showed that the crucial influence on the stability of austenite has a $\mathrm{C}$ content in this phase.

Some experimental results [46,47] suggested that an increase in a manganese content above $2.5 \%$ for conventional TRIP steels with a ferritic matrix may cause the mechanical overstabilization of retained austenite. The present study, conducted on bainite-based steels, showed that for the Mn content in a range 
from $3.3 \%$ to $4.7 \%$, it was not the case. Actually, the opposite effect took place. It was related to the complex effects of austenite enrichment in the presence of both $\mathrm{Mn}$ and $\mathrm{C}$. When the manganese concentration increases, the tendency to enrich austenite in carbon decreases [15,22]. In our case, the carbon content in the retained austenite decreased from $1.11 \%$ to $0.94 \%$ when the Mn content increased from $3.3 \%$ to $4.7 \%$.

This behavior was confirmed by thermodynamic calculations obtained by Kamoutsi et al. [48] for medium-Mn steels. Sun et al. [49] obtained similar results for 0.2C-(7-10)Mn-3Al steels. They reported that increasing the $\mathrm{Mn}$ amount from $7 \%$ to $10 \%$ resulted in the reduction of the mechanical stability of RA (Retained Austenite) due to the lower C concentration partitioned into the austenite during heat treatment. Considering the same chemical composition of the investigated steels (except $\mathrm{Mn})$, it can be concluded that the increase in Mn content by $1.4 \%$ resulted in carbon depletion of the austenite by about $0.17 \%$. Similar effect of the manganese addition was also observed by Hojo et al. [50] in 0.2C-1.5Si-(1.5-5)Mn martensitic-austenitic steels with the TRIP effect. They observed that as the Mn content increased from 1.5 to $3 \%$, the $\mathrm{C}$ content in the austenite decreased from about $1.1 \%$ to $0.7 \%$. A further increase in the Mn content to $5 \%$ led to an unfavorable reduction in $\mathrm{C}_{\gamma}$ even to $0.3 \%$. Such low carbon enrichment is related to the redistribution of carbon taking place at a lower temperature (between $M_{\mathrm{s}}$ and $M_{\mathrm{f}}$ ).

In the current work, the carbon enrichment of the austenite occurred at $400{ }^{\circ} \mathrm{C}$ as a result of the diffusion-controlled partitioning of carbon from bainitic ferrite laths. In the $3 \mathrm{Mn}-1.5 \%$ steel the $\mathrm{C}$ content at a level of $1.11 \%$ was enough to obtain bainite-austenite mixture at room temperature. In the $5 \mathrm{Mn}-1.5 \mathrm{Al}$ steel the carbon content below $1 \%$ did not decrease the $M_{\mathrm{s}}$ below room temperature. That is why a relatively high amount of MA constituents was present already at the initial state. Interlath-retained austenite was only thermodynamically stable at room temperature due to compressive stresses exerted by bainitic ferrite laths. In fact, this morphology of retained austenite has lower martensite start temperature [9,30]. The presence of MA constituents is reflected in a higher strength level whereas the $3 \mathrm{Mn}-1.5 \mathrm{Al}$ steel has better ductility.

\subsection{Effect of Thermomechanical Processing}

The direct comparison between two steels can be difficult since the applied thermomechanical processing was slightly different. The $3 \mathrm{Mn}-1.5 \mathrm{Al}$ steel was subjected to a slow cooling step after finishing rolling at $850{ }^{\circ} \mathrm{C}$. This $15 \mathrm{~s}$ stage realized at a cooling rate of $10^{\circ} \mathrm{C} / \mathrm{s}$ to $700{ }^{\circ} \mathrm{C}$, was intended to see if the steel has a potential to form any fraction of polygonal ferrite. However, the high hardenability of the steel maintained the undercooled austenite stable at $700{ }^{\circ} \mathrm{C}$. This is due to the high Mn and Mo additions in the steels, which both significantly delayed ferrite formation [1,14]. As a result, both steels did not contain polygonal ferrite. Hence, their comparison in terms of the microstructure and mechanical properties is possible. Some diffusion in the austenite should occur during the slow cooling step. However, as far as there is no polygonal ferrite, the partitioning of carbon to the austenite is not allowed. Hence, the comparison of the austenite decomposition in both steels should focus on the difference in their manganese concentrations.

The formation of retained austenite in cold-rolled medium-Mn steels is relatively well-known. During intercritical annealing, a mixture of austenite and ferrite is formed. Hence, the austenite is enriched in carbon already at this stage. A typical carbon content after this annealing step is $0.4-0.5 \%[17,21]$. This carbon enrichment and typical Mn content in a range of $7-9 \%$ are enough to keep the martensite start temperature below room temperature. Hence, the isothermal holding step is not needed. The formation of retained austenite for thermomechanically processed medium-Mn steels is completely different. There are three important differences: an initial microstructure is the deformed austenite instead of low-C martensite (1), partitioning of $C$ is difficult or impossible in industrial practice due to a lack of ferrite (2), a microstructure prior to cooling (3).

The formation of austenite-ferrite mixture from a lath-type martensite is fast during intercritical annealing. We proved in the current work that it is difficult to induce some ferrite in the deformed austenite containing 3-5\% Mn. The formation of ferrite should be enhanced under conditions of lower 
finish rolling temperature and higher accumulated strain. However, Grajcar et al. [7] reported that it is difficult even at $750{ }^{\circ} \mathrm{C}$ and for total true strain of 1 ( 0.75 in the current work). The positive microstructural aspects of the austenite decomposition in thermomechanically processed steels is that it takes place under conditions of pancake austenite. Finishing rolling at $850{ }^{\circ} \mathrm{C}$ is enough for most low-alloyed steels to be below the non-recrystallization temperature [10,11]. The plastic deformation in the non-recrystallization region in conjunction with a lowering of the finishing rolling temperature increases the austenite pancaking and resulting dislocation density [1,13]. In this case, the kinetics of the pancake austenite-bainite transformation depends significantly on the austenite deformation degree $[10,18]$.

In our case, the obtained microstructures in both steels contain fine lath products of bainite and martensite, which are isolated by layers of retained austenite. They are formed from the deformed austenite. The degree of the austenite pancaking can be enhanced by $\mathrm{Nb}$ and Mo additions. Cai et al. [30] reported that the addition of $0.22 \mathrm{wt} \% \mathrm{Mo}$ and $0.05 \mathrm{wt} \% \mathrm{Nb}$ to a $6.5 \mathrm{wt} . \% \mathrm{Mn}$ steel improved the strength-ductility combination due to the increased volume fraction and mechanical stability of retained austenite. Mo together with $\mathrm{Ti}$ and $\mathrm{Nb}$ microadditions affected a grain size due to the tendency to form complex ( $\mathrm{Ti}, \mathrm{Nb}, \mathrm{Mo}) \mathrm{C}$ precipitates, which cause the grain refinement [31,32]. Mo is also the only element which limits the cementite precipitation even at $450{ }^{\circ} \mathrm{C}$ [20]. Since there is no polygonal ferrite in the investigated steels, the whole $\mathrm{C}$ partitioning must proceed during the isothermal holding step at $400{ }^{\circ} \mathrm{C}$. The presence of retained austenite confirmed that its stabilization is possible. Taking into account the relatively small C enrichment (1.11 and $0.94 \%$ ) of the gamma phase, one can assume that the increased dislocation density and small thickness of retained austenite laths are important parameters affecting thermodynamic and mechanical stabilities of this phase in thermomechanically processed medium-Mn steels with $1.5 \% \mathrm{Al}$ content.

\section{Conclusions}

The work concerned the microstructure-property relationships in thermomechanically processed medium-Mn steels with $1.5 \% \mathrm{Al}$ content. It was found that the manganese content in a range from 3.3 to $4.7 \%$ had a significant effect on the amount and stability of retained austenite. The initial amount of this phase was $\sim 17 \%$ in the steel with a lower Mn content and $\sim 11 \%$ in the $5 \mathrm{Mn}-1.5 \mathrm{Al}$ steel. The medium-Mn content and $0.2 \%$ Mo addition increased steel hardenability significantly. The resulting effects are bainite-based microstructures without ferrite in both steels. The high amount of MA constituents was also observed in 5Mn-1.5Al steel. The Mn content determined the $\mathrm{C}$ enrichment of the retained austenite, which had a crucial effect on its mechanical stability. As the Mn content increased from 3.3 to $4.7 \%$, the carbon enrichment of the austenite decreased from 1.11 to $0.94 \%$. Both steels are characterized by high strength and moderate ductility. The steel with a lower Mn content showed the elongation $15.5 \%$ and the UTS $960 \mathrm{MPa}$. 5Mn-1.5Al steel showed a very high UTS value-1215 MPa at lower elongation of $11.5 \%$. The significant contribution to the strain hardening of the $3 \mathrm{Mn}-1.5 \mathrm{Al}$ steel had the strain-induced martensitic transformation of blocky-retained austenite grains. In the 5Mn-1.5Al steel, retained austenite layers are characterized by the lower tendency to transformation, which resulted in the lower work hardening potential. Despite the lower C content, the retained austenite layers exhibited the relatively high mechanical stability due to the presence of compressive stresses.

Author Contributions: Conceptualization, writing-review and editing, supervision: Adam Grajcar; methodology, investigation, writing — original draft preparation: Andrzej Kilarski; writing—review and editing, visualization, methodology: Aleksandra Kozlowska.

Funding: The financial support of the National Science Center, Poland is gratefully acknowledged, grant No. 2017/27/B/ST8/02864.

Conflicts of Interest: The authors declare no conflict of interest. 


\section{References}

1. Kaijalainen, A.; Vahakuopus, N.; Somani, M.; Mehtonen, S.; Porter, D.; Komi, J. The effects of finish rolling temperature and niobium microalloying on the microstructure and properties of a direct quenched high-strength steel. Arch. Metall. Mater. 2017, 62, 619-626. [CrossRef]

2. Babu, S.S.; Vogel, S.; Garcia-Mateo, C.; Clausen, B.; Morales-Rivas, L.; Caballero, F.G. Microstructure evolution during tensile deformation of a nanostructured bainitic steel. Scr. Mater. 2013, 69, 777-780. [CrossRef]

3. Grajcar, A.; Radwanski, K. Microstructural comparison of the thermomechanically treated and cold deformed Nb-microalloyed TRIP steel. Mater. Tehnol. 2014, 48, 679-683.

4. Marcisz, J.; Garbarz, B.; Burian, W.; Adamczyk, M.; Wisniewski, A. New generation maraging steel and high-carbon bainitic steel for armours. In Proceedings of the 26th International Symposium on Ballistics, Miami, FL, USA, 12-16 September 2011; pp. 1595-1606.

5. Grajcar, A. Thermodynamic analysis of precipitation processes in Nb-Ti-microalloyed Si-Al TRIP steel. J. Therm. Anal. Calorymetry 2014, 118, 1011-1020. [CrossRef]

6. Radwanski, K. Application of FEG-SEM and EBSD methods for the analysis of the restoration processes occurring during continuous annealing of dual-phase steel strips. Steel Res. Int. 2015, 86, 1379-1390. [CrossRef]

7. Grajcar, A.; Skrzypczyk, P.; Wozniak, D. Thermomechanically rolled medium-Mn steels containing retained austenite. Arch. Metall. Mater. 2014, 59, 1691-1697. [CrossRef]

8. Opiela, M. Thermomechanical treatment of Ti-Nb-V-B micro-alloyed steel forgings. Mater. Tehnol. 2014, 48, 587-591.

9. Somani, M.C.; Porter, D.A.; Karjalainen, L.P.; Suikkanen, P.P.; Misra, R.D.K. Process design for tough ductile martensitic steels through direct quenching and partitioning. Mater. Today Proc. 2015, 2S, 631-634. [CrossRef]

10. Opiela, M.; Grajcar, A. Elaboration of forging conditions on the basis of the precipitation analysis of MX-type phases in microalloyed steels. Arch. Civ. Mech. Eng. 2012, 12, 427-435. [CrossRef]

11. Timokhina, I.B.; Pereloma, E.V.; Hodgson, P.D. Microstructure and mechanical properties of C-Si-Mn(-Nb) TRIP steels after simulated thermomechanical processing. Mater. Sci. Technol. 2001, 17, 135-140. [CrossRef]

12. Zhao, J.; Jiang, Z. Thermomechanical processing of advanced high strength steels. Prog. Mater Sci. 2018, 94, 174-242. [CrossRef]

13. Skalova, L.; Divisova, R.; Jandova, D. Thermo-mechanical processing of low-alloy TRIP steel. J. Mater. Process. Technol. 2006, 175, 387-392. [CrossRef]

14. Hu, B.; Luo, H. Microstructures and mechanical properties of $7 \mathrm{Mn}$ steel manufactured by different rolling processes. Metals 2017, 7, 464. [CrossRef]

15. Sugimoto, K.; Tanino, H.; Kobayashi, J. Impact toughness of medium-Mn transformation-induced plasticity-aided steels. Steel Res. Int. 2015, 86, 1151-1160. [CrossRef]

16. Steineder, K.; Beal, C.; Krizan, D.; Dikovits, M.; Sommitsch, C.; Schneider, R. Hot deformation behavior of a third generation advanced high strength steel with a medium-Mn content. Key Eng. Mater. 2015, 651-653, 120-125. [CrossRef]

17. Yang, F.; Luo, H.; Pu, H.; Zhang, S.; Dong, H. On the characteristics of Portevin-Le Chatelier bands in cold-rolled 7Mn steel showing transformation-induced plasticity. Int. J. Plast. 2018, 103, 188-202. [CrossRef]

18. Aydemir, B.; Zeytin, H.K.; Guven, G. Investigation of Portevin-Le Chatelier effect of hot-rolled Fe-13Mn-0.2C-1Al-1Si TWIP steel. Mater. Tehnol. 2016, 50, 511-516. [CrossRef]

19. Grajcar, A.; Kozlowska, A.; Grzegorczyk, B. Strain hardening behavior and microstructure evolution of high-manganese steel subjected to interrupted tensile tests. Metals 2018, 8, 122. [CrossRef]

20. De Cooman, B.C. Structure-Properties relationship in TRIP steels containing carbide-free bainite. Curr. Opin. Solid State Mater. Sci. 2004, 8, 285-303. [CrossRef]

21. Pereloma, E.V.; Gazder, A.A.; Timokhina, I.B. Retained austenite: Transformation-Induced Plasticity. In Encyclopedia of Iron, Steel, and Their Alloys; Taylor and Francis: New York, NY, USA, 2016; pp. 3088-3103. [CrossRef]

22. Aydin, H.; Jung, I.H.; Essadiqi, E.; Yue, S. Twinning and Tripping in 10\% Mn steels. Mater. Sci. Eng. A 2014, 591, 90-96. [CrossRef]

23. Kurc-Lisiecka, A.; Piwnik, J.; Lisiecki, A. Laser welding of new grade of advanced high strength steel strenx 1100 MC. Arch. Metall. Mater. 2017, 62, 1651-1657. [CrossRef] 
24. Gorka, J. Welding thermal cycle-triggered precipitation processes in steel S700MC subjected to the thermo-mechanical control processing. Arch. Metall. Mater. 2017, 62, 321-326. [CrossRef]

25. Ding, W.; Hedstrom, P.; Li, Y. Heat treatment, microstructure and mechanical properties of a C-Mn-Al-P hot dip galvanizing TRIP steel. Mater. Sci. Eng. A 2016, 674, 151-157. [CrossRef]

26. Girault, E.; Mertens, A.; Jacques, P.; Houbaert, Y.; Verlinden, B.; Van Humbeeck, J. Comparison of the effects of silicon and aluminium on the tensile behavior of multiphase TRIP-assisted steels. Scr. Mater. 2001, 44, 885-892. [CrossRef]

27. Kucerova, L.; Bystriansky, M. Comparison of thermomechanical treatment of C-Mn-Si-Nb and C-Mn-Si-Al-Nb TRIP steels. Procedia Eng. 2017, 207, 1856-1861. [CrossRef]

28. Kaar, S.; Krizan, S.; Schwabe, J.; Hofmann, H.; Hebesberger, T.; Commenda, C.; Samek, L. Influence of the Al and Mn content on the structure-property relationship in density reduced TRIP-assisted sheet steels. Mater. Sci. Eng. A 2018, 735, 475-486. [CrossRef]

29. Grajcar, A.; Kwasny, W.; Zalecki, W. Microstructure-property relationships in TRIP aided medium-C bainitic steel with lamellar retained austenite. Mater. Sci. Technol. 2015, 31, 781-794. [CrossRef]

30. Cai, M.; Li, Z.; Chao, Q.; Hodgson, P.D. A novel Mo and Nb microalloyed medium Mn TRIP steel with maximal ultimate strength and moderate ductility. Metall. Mater. Trans. A 2014, 45A, 5624-5634. [CrossRef]

31. Lee, D.; Kim, J.K.; Lee, S.; Lee, K.; De Cooman, B.C. Microstructures and mechanical properties of Ti and Mo micro-alloyed medium Mn steel. Mater. Sci. Eng. A 2017, 706, 1-14. [CrossRef]

32. Pan, H.; Ding, H.; Cai, M. Microstructural evolution and precipitation behavior of the warm-rolled medium Mn steels containing $\mathrm{Nb}$ or Nb-Mo during intercritical annealing. Mater. Sci. Eng. A 2018, 736, 375-382. [CrossRef]

33. Misra, R.D.K.; Kumar, B.R.; Somani, M.; Karjalainen, P. Deformation processes during tensile straining of ultrafine/nanograined structures formed by reversion in metastable austenitic steels. Scr. Mater. 2008, 59, 79-82. [CrossRef]

34. Lun, N.; Saha, D.C.; Macwan, A.; Pan, H.; Wang, L.; Goodwin, F.; Zhou, Y. Microstructure and mechanical properties of fibre laser welded medium manganese TRIP steel. Mater. Des. 2017, 131, 450-459. [CrossRef]

35. Di, X.; Deng, S.; Wang, B. Effect of pulse current on mechanical properties and dendritic morphology of modified medium manganese steel welds metal. Mater. Des. 2015, 66, 169-175. [CrossRef]

36. Muruyama, H. X-ray measurement of retained austenite volume fraction. J. Jpn. Soc. Heat Treat. 1977, 17, $198-204$.

37. Dyson, D.J. Effect of alloying additions on the lattice parameter of austenite. J. Iron Steel Inst. 1970, 5, 469-474.

38. Jacques, P.J.; Furnemont, Q.; Lani, F.; Pardoen, T.; Delannay, F. Multiscale mechanics of TRIP-assisted multiphase steels: I. Characterization and mechanical testing. Acta Mater. 2007, 55, 3681-3693. [CrossRef]

39. Mukherjee, M.; Mohanty, O.N.; Hashimoto, S.; Hojo, T.; Sugimoto, K. Strain-induced transformation behaviour of retained austenite and tensile properties of TRIP-aided steels with different matrix microstructure. ISIJ Int. 2006, 46, 316-324. [CrossRef]

40. Zhao, L.; Sietsma, J.; Van der Zwaag, S. Phase transformations and microstructural evolution in aluminium-containing TRIP steels. Steels Mater. Power Plants 1999, 7, 77-82.

41. Caballero, F.G.; Chao, J.; Cornide, J.; Garcia-Mateo, C.; Santofimia, M.J.; Capdevila, C. Toughness deterioration in advanced high strength bainitic steels. Mater. Sci. Eng. A 2009, 525, 87-95. [CrossRef]

42. Grajcar, A.; Kilarski, A.; Radwański, K.; Swadźba, R. Microstructural features of strain-induced martensitic transformation in medium-Mn steels with metastable retained austenite. Arch. Metall. Mater. 2014, 59, 1673-1678. [CrossRef]

43. Gomez, M.; Garcia, C.I.; De Ardo, A.J. The role of new ferrite on retained austenite stabilization in Al-TRIP steels. ISIJ Int. 2010, 50, 139-146. [CrossRef]

44. Jacques, P.J.; Girault, E.; Mertens, A.; Verlinden, B.; Van Humbeeck, J.; Delannay, F. The developments of cold-rolled TRIP-assisted multiphase steels. Al-alloyed TRIP-assisted multiphase steels. ISIJ Int. 2001, 41, 1068-1074. [CrossRef]

45. Soliman, M.; Palkowski, H. On factors affecting the phase transformation and mechanical properties of cold-rolled transformation-induced-plasticity-aided steel. Metall. Mater. Trans. A 2008, 39, 2513-2527. [CrossRef]

46. Kim, S.J.; Lee, C.G.; Choi, I.; Lee, S. Effects of heat treatment and alloying elements on the microstructures and mechanical properties of $0.15 \% \mathrm{C}$ transformation induced plasticity-aided cold-rolled steel sheets. Metall. Mater. Trans. A 2001, 32, s505-s514. [CrossRef] 
47. Jacques, P.J.; Girault, E.; Catlin, T.; Geerlofs, N.; Kop, T.; Van der Zwaag, S.; Delannay, F. Bainite transformation of low carbon Mn-Si TRIP-assisted multiphase steels: Influence of silicon content on cementite precipitation and austenite retention. Mater. Sci. Eng. A 1999, 273, 475-479. [CrossRef]

48. Kamoutsi, H.; Gioti, E.; Haidemenopoulos, G.N.; Cai, Z.; Ding, H. Kinetics of solute partitioning during intercritical annealing of a medium-Mn steel. Metall. Mater. Trans. A 2015, 46, 4841-4846. [CrossRef]

49. Sun, B.; Fazeli, F.; Scott, C.; Guo, B.; Aranas, C., Jr.; Chu, X.; Jahazi, M.; Yue, S. Microstructural characteristics and tensile behavior of medium manganese steels with different manganese additions. Mater. Sci. Eng. A 2018, 729, 496-507. [CrossRef]

50. Hojo, T.; Kobayashi, J.; Kochi, T.; Sugimoto, K. Effects of thermomechanical processing on microstructure and shear properties of 22SiMnCrMoB TRIP-aided martensitic steel. Iron Steel Technol. 2015, 12, 102-110.

(c) 2018 by the authors. Licensee MDPI, Basel, Switzerland. This article is an open access article distributed under the terms and conditions of the Creative Commons Attribution (CC BY) license (http:/ / creativecommons.org/licenses/by/4.0/). 